\title{
Inflammatory bowel disease, the oral contraceptive pill and pregnancy
}

ROBERT N ALLAN MD PhD FRCP

RN ALLAN. Inflammatory bowel disease, the oral contraceptive pill and pregnancy. Can J Gastroenterol 1994;8(7):430-432. This paper summarizes our current knowledge of the role of the oral contraceptive pill in the pathogenesis of inflammatory bowel disease (IBD), followed by a review of fertility in women and men. IBD and pregnancy, including the impact on the fetus and the mother with ulcerative colitis or Crohn's disease, is considered. The safety of drug treatment during pregnancy, the outcome of surgical treatment during pregnancy and the problems that may be encountered during pregnancy in patients with an ileostomy or ileo-anal pouch are discussed, followed by a review of the short and long term prognosis of ulcerative colitis and Crohn's disease partition.

Key Words: Crohn's disease, Inflammatory bowel disease, Oral contraceptive agents, Pregnancy, Ulcerative colitis

\section{Maladie inflammatoire de l'intestin, contraception orale et grossesse}

RÉSUMÉ : Cet article résume les connaissances accumulées à ce jour sur le rôle des contraceptifs oraux dans la pathogenèse de la maladie inflammatoire de l'intestin (MII), suivi d'une synthèse sur la fertilité chez la femme et chez l'homme. Les MII et la grossesse, $y$ compris l'impact sur le foetus et la mère atteinte de colite ulcéreuse ou de maladie de Crohn, sont passées en revue. L'innocuité des médicaments durant la grossesse, l'issue des traitements chirurgiraux en cours de grossesse et les problèmes qui peuvent être rencontrés en cours de grossesse chez les patientes porteuses d'une iléostomie ou d'un réservoir iléo-anal sont présentés, suivi d'une revue du pronostic à cours et à long terme de la colite ulcéreuse et de la maladie de Crohn.

Queen Elizabeth Hospital, Birmingham, United Kingdom

Correspondence: Dr Robert Allan, Queen Elizabeth Hospital, Edgbaston, Birmingham B15 2TH, United Kingdom

This paper was presented at the Trends in Inflammatory Bowel Disease Therapy meeting, April 6 to 9, 1994, held in Victoria, British Columbia. This paper has also been published in Sutherland LR, et al, eds. Inflammatory Bowel Disease: Basic Research, Clinical Implications and Trends in Therapy. Boston, Dordrecht and London: Kluwer Academic Publishers, 1994
Qeveral large studies have Shown a small increase in the prevalence of ulcerative colitis and Crohn's disease among users of the oral contraceptive pill compared with nonusers. The differences were not large enough to reach statistical significance. For example, in the study of Logan et al (1) in 1989 the relative risk of developing Crohn's disease, when users were compared with nonusers, was 1.7; for patients with ulcerative colitis the relative risk was 1.3. Neither reached statistical significance.

In a study by Lesko et al (2) in 1985 the excess among patients with Crohn's disease who used the oral contraceptive pill, compared with nonusers, showed an overall relative risk of 1.9 , but the risk was greatly increased in recent users (relative risk 4.3) compared with exusers (relative risk 1.2). Most studies have shown that this small excess relative risk returns to normal when the oral contraceptive is discontinued.

What are we to make of these data? The overwhelming message is that the oral contraceptive pill is safe and is only rarely associated with the development of ulcerative colitis or Crohn's disease. The data could probably be best interpreted as suggesting that a small subset of individuals develop an oral contra- 
ceptive pill-related colitis indistinguishable from ulcerative colitis and Crohn's colitis which resolves on pill withdrawal. The clinical message is that for any oral contraceptive user with ulcerative colitis or Crohn's disease who has not responded to standard therapy, withdrawal of the oral contraceptive pill should be considered, provided of course that alternative contraceptive measures are offered at the same time.

\section{FERTILITY IN WOMEN}

Ulcerative colitis: Several excellent clinical studies have shown that fertility in women with ulcerative colitis is normal and identical to that in the general population. Thus in a large series of married women with ulcerative colitis, $81 \%$ conceived normally, $12 \%$ voluntarily avoided pregnancy, $2 \%$ of husbands had oligospermia and 5\% were unable to have children. These figures are equivalent to the general population; eg, $10 \%$ of marriages in the United Kingdom are childless (3).

Crohn's disease: There is good evidence that the fertility of women with Crohn's disease is impaired. Mayberry and Weterman (4) undertook an extensive European study and showed that patients with Crohn's disease had only half the number of children compared with healthy control couples. There are several good reasons to explain this finding, but the exact explanation has not yet been defined. The possibilities include: the severity of disease, avoiding pregnancy on medical advice, dyspareunia, particularly in the presence of severe perianal disease; and impaired ovulation or fallopian tube blockage following pelvic sepsis complicating Crohn's disease.

\section{FERTILITY IN MEN}

It is well recognized that fertility may be affected in men taking sulfasalazine by reducing both the total sperm count and sperm motility, but that this effect is reversible after withdrawing the drug (5). The sulfapyridine moiety is probably responsible because this problem was not found with other 5-aminosalicylic acid (5-ASA) preparations. There is evidence that active
Crohn's disease may cause oligospermia in some men and thus directly account for infertility.

\section{IMPACT OF INFLAMMATORY BOWEL DISEASE ON PREGNANCY}

Ulcerative colitis - Impact on the fetus: A large number of studies have shown that pregnancy in ulcerative colitis usually results in a normal, full term baby. Low birth weight or fetal abnormality are no greater than that expected in the general population.

Willoughby (6) summarized the 14 major studies on the outcome of pregnancy in women with ulcerative colitis and showed that among 1466 pregnancies, a normal live birth resulted in $1238(84 \%)$. The incidence of spontaneous abortion ( $8 \%)$, therapeutic abortion (5\%), congenital abnormalities $(1 \%)$ and stillbirth (1\%) was similar to that in the healthy population.

Ulcerative colitis - Impact on the mother: In patents with established ulcerative colitis in remission at conception, the disease is likely to remain quiescent throughout pregnancy and the puerperium. Active disease at conception is more likely to be associated with recurrence of symptoms during pregnancy which are most common during the first trimester of pregnancy. In the past, relapse of disease in the puerperium was accepted as a commonplace finding but this has not been substantiated in practice. Occasionally ulcerative colitis has arisen for the first time during pregnancy.

Crohn's disease - Impact on the fetus: Excellent data on Crohn's disease and pregnancy are available from a recent study from Woolfson and colleagues (7). They studied 78 pregnancies among 50 patients with Crohn's disease. The incidence of spontaneous abortion, babies small for dates, premature birth, respiratory distress and fetal abnormality were similar to that expected in the general population.

At conception, $79 \%$ of women in this study had inactive (Crohn's disease, and in general a poorer fetal outcome was found among patents with active disease at the time of conception. There was no evidence that ap- propriate medical or surgical treatment affected the outcome for the fetus.

Crohn's disease - Impact on the mother: The outlook for the mother is particularly favourable if Crohn's disease is quiescent at conception; in this circumstance, $70 \%$ of Crohn's disease patients remain symptom-free during pregnancy and puerperium. Individual case reports have described Crohn's disease presenting either during pregnancy or shortly after delivery, but both these events are distinctly unusual.

From these data, clear guidelines emerge: the overall prospects for pregnancy and Crohn's disease are good, but patients should avoid becoming pregnant when their disease is active because it impairs the outcome of both the pregnancy and the underlying Crohn's disease.

\section{SURGICAL TREATMENT DURING PREGNANCY}

There are number of individual case reports and small series reporting a satisfactory outcome in pregnant patients undergoing surgery for inflammatory bowel disease (IBD), but the reported numbers are too small to draw reliable conclusions.

\section{PREGNANCY IN ILEOSTOMY PATIENTS}

Willoughby (8) has summarized nine studies of patients who became pregnant after surgical treatment with an ileostomy for ulcerative colitis. Among 119 pregnancies the outcome for the fetus was similar to that expected in the general population. Among the 119 pregnancies there were 18 stoma problems including intestinal obstruction (nine), stoma prolapse (five), leakage from around the stoma (two), intussusception (one) and one further undefined problem.

Individual case reports and small series of pouch patients who have undergone successful and uneventful pregnancy have been reported (9).

\section{DRUG TREATMENT DURING PREGNANCY}

Sulfasalazine: While high dose sulfonamides can cause congenital abnormalities in the offspring of pregnant 
rats, there are no published reports of sulfasalazine-associated congenital abnormalities in humans. Indeed, extensive studies of sulfasalazine in pregnancy have shown no adverse effects on the chances of producing a normal child (10). Recent studies of oral 5-ASA for IBD in pregnancy have shown that its use is both safe for the fetus and mother (11).

Metronidazole: There are no large reports of the use of metronidazole during pregnancy in patents with IBD. However, there are several large studies of pregnant patients taking metronidazole during pregnancy for trichomonas vaginalis. No adverse effect on the fetus was found. In particular, birth weight, the incidence of stillbirths and congenital abnormalities was exactly that expected in the general population (12).

Immunosuppressive therapy: There are no large studies of the use of azathioprine during pregnancy in patients with IBD. The nearest equivalent is data analysis from those women receiving azathioprine during pregnancy following renal transplantation. The data collected from 49 papers describe the outcome of 434 pregnancies and 375 women of whom $356(82 \%)$ resulted in

\section{REFERENCES}

1. Logan RFA, Kay CR, Scott L.

The pill, smoking and inflammatory

bowel disease: results from

the RCGP oral contraceptive

study. Int J Epidemiol

1989;18:105-7.

2. Lesko SM, Kaufman DW, Rosenberg L, et al. Evidence for an increased risk of Crohn's disease in oral contraceptive users.

Gastroenterology 1985;89:1046-9.

3. Willoughby CP, Truelove SC. Ulcerative colitis and pregnancy. Gut 1980;21:469-74.

4. Mayberry JF, Weterman IT. European survey of fertility and pregnancy in women with Crohn's disease: a case-control study by European collaborative group. Gut 1986;27:821-5.

5. Cann P, Holdsworth CD. Reversal of male infertility on changing treatment overtly normal infants, a figure close to that expected in the general population (personal communication).

\section{BREAST FEEDING IN IBD PATIENTS TAKING SULFASALAZINE}

Sulfasalazine and sulfapyridine are secreted into breast milk, and theoretically sulfasalazine could bind to circulating albumen and displace unconjugated bilirubin. However, it is now clear that sulfasalazine binds to albumen at sites other than high affinity sites for bilirubin and is not therefore a risk factor for the development of kernicterus in the breast-fed infant (13).

\section{LONG TERM OUTCOME AFTER PREGNANCY}

Ulcerative colitis: The symptomatic pattern of ulcerative colitis in the first pregnancy cannot be used to predict the symptomatic pattern in subsequent pregnancies.

Crohn's disease: Interesting evidence is emerging that parity in women with Crohn's disease improves the long term outcome in that women in the postpartum period have fewer exacerba-

from sulphasalazine to 5 amino salicylate. Lancet 1984;i:1119.

6. Willoughby CP. Fertility, pregnancy and inflammatory bowel disease. In: Allan RN, Keighley MRB, Hawkins CF, Alexander-Williams J, eds. Inflammatory Bowel Diseases, 2nd edn. Edinburgh: Churchill Livingstone, 1990:547-58.

7. Woolfson K, Cohen Z, McLeod RS. Crohn's disease and pregnancy. Dis Colon Rectum 1990;33:869-73.

8. Willoughby CP. Fertility, pregnancy and inflammatory bowel disease. In: Allan RN, Keighley MRB, Hawkins CF, Alexander-Williams J, eds. Inflammatory Bowel Diseases, 2nd edn. Edinburgh: Churchill Livingstone, 1990:555.

9. Metcalf A, Dozois RR, Beart RW, Wolff BG. Pregnancy following ileal pouch-anal anastomosis. Dis Colon Rectum 1985;28:859-61. tions and undergo fewer resections than nonparous controls with Crohn's disease.

This beneficial effect was evident in both patients with distal ileal and colonic Crohn's disease. In nonparous patients with ileal disease after a mean follow-up of 15 years, the mean number of resections per patient was $1.52 \mathrm{com}$ pared with 1.17 for those who had been pregnant before diagnosis. The interval from first to second resection was 10 years in nonparous patients and 13 years in parous patients. Similar data were evident in patients with colonic Crohn's disease, where the number of resections per patient was less in those who had been pregnant before diagnosis and the interval from first to subsequent resection was much longer (14). The mechanism for this protective effect of pregnancy on the outcome of Crohn's disease is uncertain, but pregnancy could influence the natural history of Crohn's disease either by decreasing immune responsiveness or by retarding fibrous stricture formation which is the most common indication for surgical intervention, particularly in patents with distal ileal disease.

10. Nielson $\mathrm{OH}$, Andreasson B, Bondesen $\mathrm{S}$, Jacobson O, Jarnum S. Pregnancy in Crohn's disease. Scand J Gastroenterol 1984;19:724-32.

11. Habal FM, Hui G, Greenberg GR. Oral 5-aminosalicylic acid for inflammatory bowel disease in pregnancy: safety and clinical course. Gastroenterology 1993;105:1057-60.

12. Piper JM, Mitchell EF, Ray WA. Prenatal use of metronidazole and birth defects: No association. Obstet Gynecol 1993;82:348-52.

13. Jarnerot G, Anderson S, Esbjorner E, Sandstrom B, Brodersen R. Albumin reserve for binding of bilirubin in maternal and cord serum under treatment with sulphasalazine. Scand J Gastroenterol 1981;16:1049-55.

14. Nwokolo CU, Tan WC, Andrews HA, Allan RN. Surgical resections in parous patients with distal ileal and colonic Crohn's disease. Gut 1994;35:220-3. 


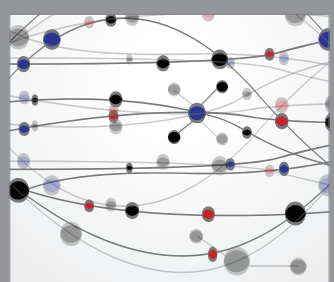

The Scientific World Journal
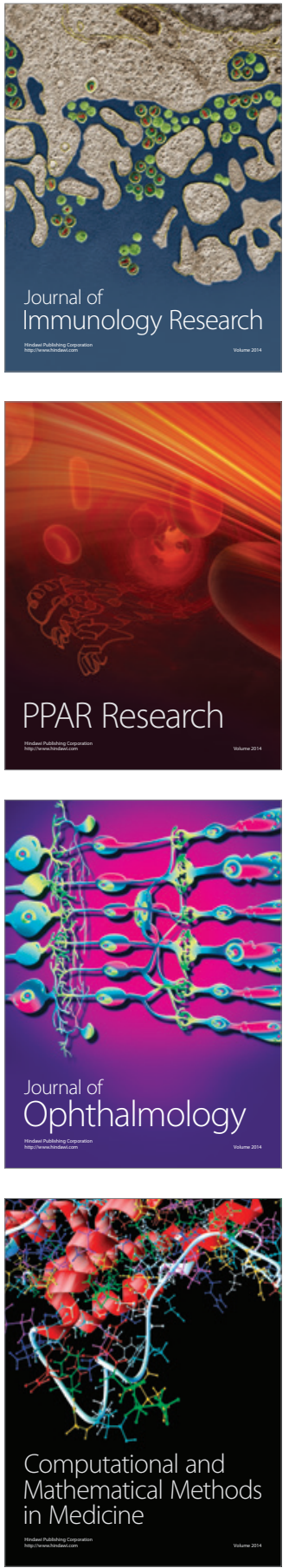

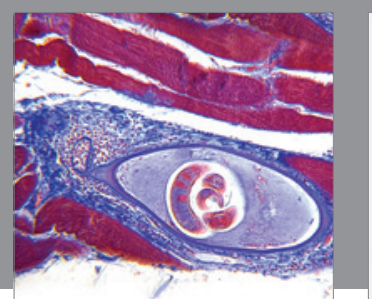

Gastroenterology Research and Practice

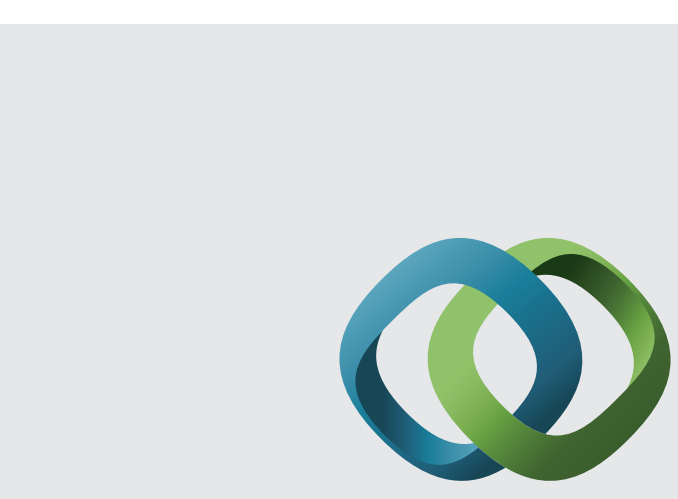

\section{Hindawi}

Submit your manuscripts at

http://www.hindawi.com
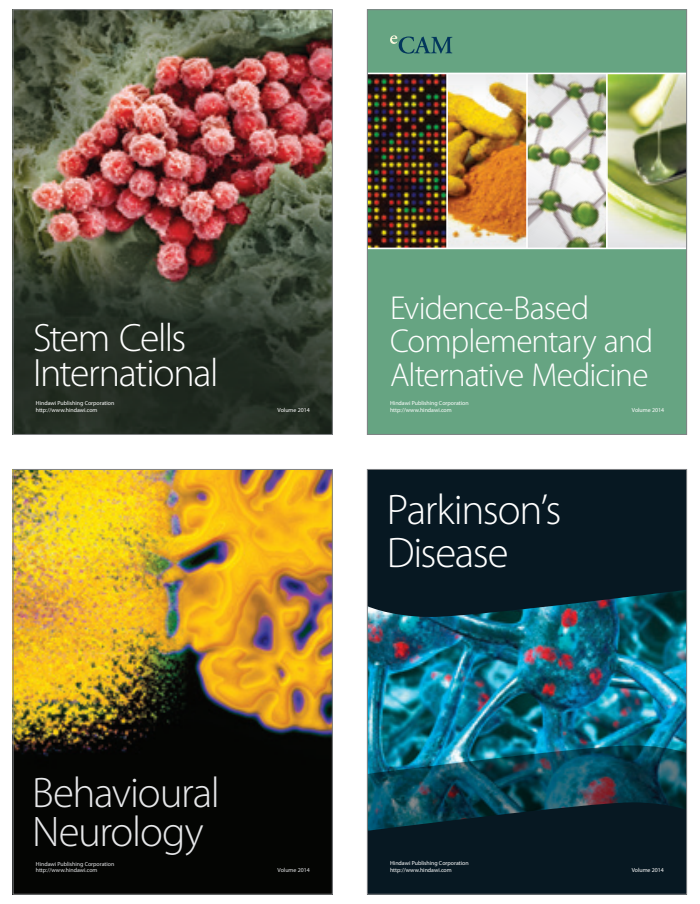
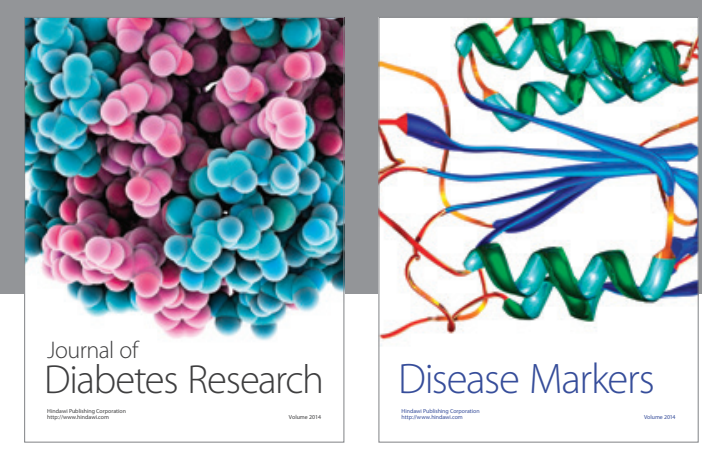

Disease Markers
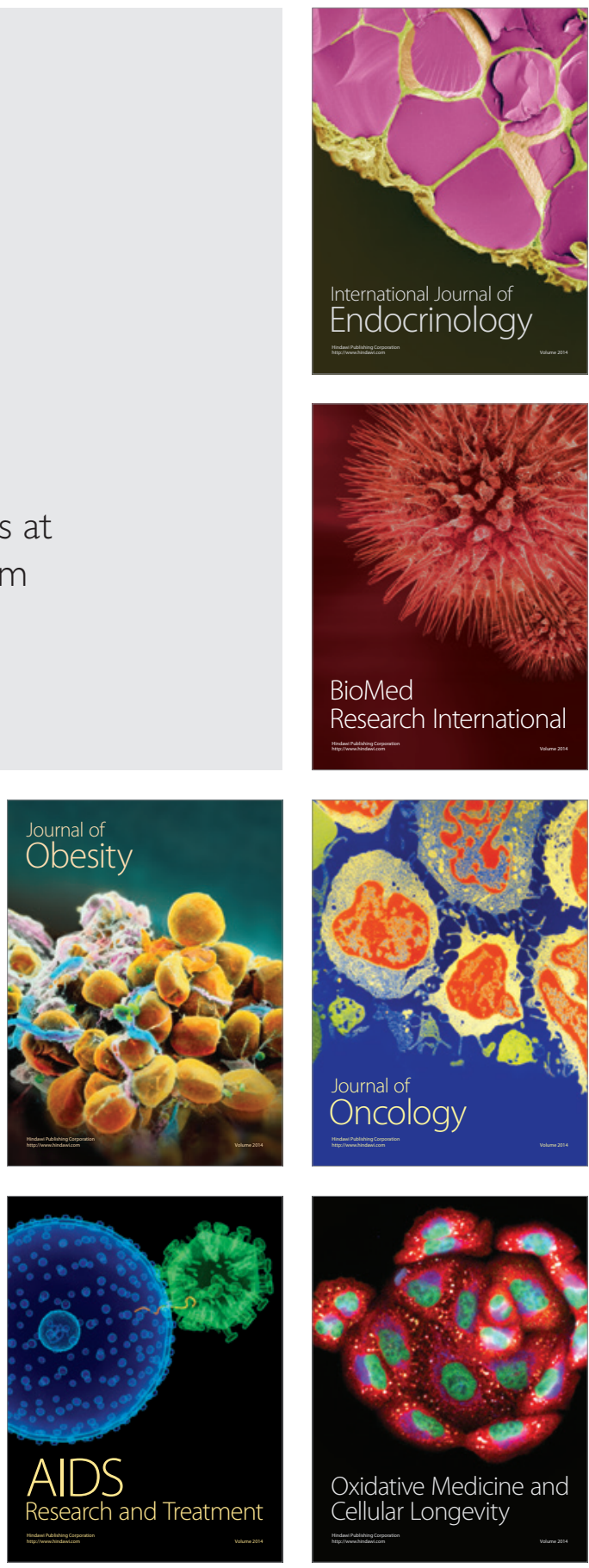